\title{
AVALIAÇÃO DO APROVEITAMENTO DE BORRA DE TINTA GERADA EM SISTEMAS DE PINTURA DE PROCESSO METALÚRGICO
}

\author{
B. BITTELBRUNN ${ }^{1}$, B. L. B. PERINI ${ }^{2}$ e N. SELLIN ${ }^{3}$ \\ ${ }^{1}$ Universidade da Região de Joinville, Departamento de Engenharia Ambiental \\ ${ }^{2,3}$ Universidade da Região de Joinville, Mestrado em Engenharia de Processos \\ E-mail para contato: nsellin@yahoo.com.br
}

\begin{abstract}
RESUMO - Neste trabalho, foi avaliado o aproveitamento de borra de tinta a base de solvente gerada em cabines de pintura de peças de indústria metalúrgica. A recuperação da borra de tinta foi realizada a partir da adição de solvente, moagem e filtração. A tinta obtida foi caracterizada e aplicada em amostras de aço comum e de ferro cinzento/nodular. As amostras pintadas foram caracterizadas por resistência à corrosão, ciclagem térmica, aderência e espessura de camada, e comparadas com amostras pintadas com tintas não recicladas. Análise econômica foi realizada visando comparar custos relacionados à reciclagem da borra de tinta com os de destinação em aterro industrial. A tinta reciclada apresentou características e propriedades semelhantes a tintas usualmente empregadas pela indústria metalúrgica, sendo aprovada nos testes de qualidade da pintura, podendo ser empregada como tinta de fundo. A reciclagem da borra de tinta apresentou menor custo em relação à disposição em aterro industrial.
\end{abstract}

\section{INTRODUÇÃO}

Segundo a Associação Brasileira de Fabricantes de Tintas (ABRAFATI), em 2013, o faturamento da indústria de tintas foi cerca de $\mathrm{R} \$ 9,120$ bilhões em um volume produzido de 1,426 bilhão de litros, sendo que 12\% deste valor foram destinados à indústria geral (eletrodomésticos, móveis, autopeças, naval, aeronáutica, tintas de manutenção, etc.). Uma demanda elevada e cada vez mais crescente no uso de tintas é observada, indicando o aumento na geração de resíduos, principalmente, os gerados nas cabines de pintura em processos por via úmida, que utilizam água para remoção de uma parte da tinta dispersa no meio durante a pintura de peças metálicas, gerando como resíduo um material pastoso, denominado borra de tinta (Souza, 2009). Desta forma, a borra de tinta terá na sua composição além da água, as substâncias presentes nas tintas usadas no processo de pintura, como resinas poliméricas (acrílicas, vinílicas, poliuretânicas, poliésteres, epóxis, melaminas); solventes orgânicos (alifáticos, aromáticos, alcoóis, cetonas e éter de petróleo); além de compostos relacionados aos pigmentos, aditivos e cargas, como óxidos de ferro, ftalocianinas, sulfocromato de chumbo, cromato molibdato sulfato de chumbo, acetato de amila, acetato de butila, acetato de butilglicol, acetato de etilglicol, dióxido de titânio, carbonato de cálcio, entre outros (Fazenda, 1995). O resíduo borra de tinta a base de solvente é classificado segundo a NBR 10.004/2004 como resíduo perigoso Classe I, devido às suas características químicas e por sua inflamabilidade e toxicidade. Geralmente, a borra de tinta é encaminhada para disposição em aterros industriais, os quais 


\section{9 a 22 de outubro de 2014 \\ Florianópolis/SC}

apresentam custos elevados e estão cada vez mais escassos, principalmente, devido às seguintes condições: concentração em torno de grandes cidades, nas quais áreas para deposição são escassas; a recusa da população em aceitar um depósito de lixo em sua vizinhança; e as crescentes exigências técnicas para tratamento e deposição (John, 2000).

Considerando que atualmente na indústria metalúrgica são geradas grandes quantidades deste resíduo por mês, o reprocessamento desta borra e sua transformação em tinta poderão diminuir custos, eliminar passivos e preservar a longevidade desses aterros. O processo de recuperação de borra de tinta mais empregado é o químico, a partir do qual a borra é dissolvida em um solvente orgânico, liquefazendo-a e transformando-a novamente no estado de tinta, esta chamada de segunda linha (Johnson e Slater, 1991; Brito e Cunha, 2009). Para que este processo possa ser viabilizado, é necessário realizar uma prospecção dos valores econômicos e, principalmente, de viabilidade técnica para a recuperação das borras de tintas, a qual está relacionada, principalmente aos custos operacionais, logísticos e de utilização do produto gerado após processamento.

Visando a valorização de resíduos, neste trabalho, foi avaliado o aproveitamento de borra de tinta a base de solvente gerada nas cabines de pintura de peças de uma indústria metalúrgica e realizada a análise econômica, considerando os custos relacionados à destinação da borra em aterros e os relacionados à sua recuperação na forma de tinta.

\section{METODOLOGIA}

\subsection{Recuperação e caracterização da borra de tinta}

Para os ensaios, foram coletados 200 litros de borra de tinta a base de solvente (tolueno) proveniente da cabine de pintura de uma indústria metalúrgica, e encaminhados para processamento em uma indústria de reciclagem química de tintas. Nesta, a borra de tinta foi misturada com $15 \%$ (v/v) de solvente orgânico conhecido como Tíner (composto por hidrocarbonetos aromáticos, álcool, cetonas e glico-ésteres) em um tanque com agitação e depois triturada em um moinho de bolas para diminuir a granulometria das partículas presentes e ocasionar melhor dispersão das mesmas no solvente. Posteriormente, foi submetida à filtração por escoamento em uma tela de aço de baixa porosidade para retenção das partículas sólidas remanescentes, e enviadas para envase. A tinta reciclada foi caracterizada em laboratório especializado por análises químicas e físicas, para determinação dos parâmetros regulamentados pela Norma Regulamentadora no. 15 do Ministério do Trabalho e Emprego (MTE, 2014) e os resultados foram comparados com os de tintas não recicladas (preta e branca), usualmente empregadas pela indústria na pintura de peças metálicas.

\subsection{Pintura dos corpos de prova metálicos}

Para os testes de pintura, com base na NBR10546/88, foram preparados 14 corpos de prova no total, em aço comum e compostos por $50 \%$ ferro cinzento/50\% ferro nodular. Os corpos de prova foram pintados com pistola tipo convencional com caneca (pulverização por ar comprimido), sendo aplicadas duas demãos de tinta reciclada e não recicladas, seguindo a NBR13006/93. Após a pintura, os corpos de prova foram deixados secar no ambiente por $20 \mathrm{~min}$. 


\section{9 a 22 de outubro de 2014 \\ Florianópolis/SC}

\subsection{Caracterização dos corpos de prova}

Ciclagem térmica: foi empregada para avaliar possíveis alterações da tinta quando submetidas a temperaturas elevadas. Os corpos de prova pintados foram colocados em uma câmara climática (modelo: SE-300-2-2 Thermotron) e aquecidos de 40 até $80{ }^{\circ} \mathrm{C}$, em taxa de aquecimento de $0,4{ }^{\circ} \mathrm{C} / \mathrm{h}$, por 100 horas. $\mathrm{O}$ procedimento adotado foi baseado em normas internas da empresa. Após o teste, as amostras foram analisadas por inspeção visual. Os testes foram realizados em corpos de prova de aço comum e ferro nodular/cinzento pintados com a tinta reciclada, totalizando duas amostras.

Corrosão por exposição em névoa salina (salt spray): foi efetuada seguindo procedimentos da NBR 8094/83. Primeiro, foi realizado um corte vertical de aproximadamente $4 \mathrm{~cm}$ nos corpos de prova de aço comum pintados com as tintas reciclada e não reciclada, para verificar se houve migração da oxidação da peça metálica para a tinta. Após, os corpos de prova foram submetidos a uma câmara de salt spray por 100 horas e foi verificado por inspeção visual se as amostras sofreram ou não corrosão. O teste foi realizado em 4 corpos de prova pintados com tinta reciclada, uma amostra com tinta não reciclada de cor preta e uma de cor branca e uma amostra com tinta reciclada como tinta de fundo e a tinta branca como acabamento.

Determinação da espessura de camada: foi realizada seguindo norma interna da empresa (referência ITSPA - 504) utilizando aparelho Politest - modelo 1250FN. Primeiro, foi utilizada uma lixa para retirar a tinta em uma área superficial dos corpos de prova. Depois, a sonda do aparelho medidor foi posicionada sobre a superfície da amostra (sem camada) e a espessura de camada de tinta depositada foi medida. $\mathrm{O}$ teste foi realizado com a mesma amostragem do teste de corrosão.

Teste de aderência: foi realizado empregando o método de corte em grade, segundo a NBR 11003/2009. Este método foi aplicado, devido à película de tinta não ultrapassar $70 \mu \mathrm{m}$ em nenhum dos corpos de prova nos testes de medição de camada. O percentual de aderência também foi determinado. O teste foi realizado com a mesma amostragem do teste de corrosão. Não foram realizados testes de aderência e espessura de camada em amostras de ferro nodular/cinzento, devido à dificuldade de se medir a camada de tinta por causa da rugosidade superficial observada nestas.

\subsection{Análise de viabilidade econômica}

Foi elaborado um cenário representando a viabilidade econômica do processo de reciclagem da borra de tinta para a indústria metalúrgica, considerando o período de um ano. Para isso, foram relacionados os custos efetivos de transporte e destinação do resíduo para aterro industrial versus transporte e recuperação em empresa especializada em reciclagem de derivados de tinta. $\mathrm{O}$ cenário foi representado por cálculos simples, os quais foram transformados em diferenciais percentuais.

\section{RESULTADOS E DISCUSSÃO}

\subsection{Características físicas e químicas da tinta reciclada e não recicladas}

$\mathrm{Na}$ Tabela 1 estão apresentados os resultados da caracterização física e química da tinta reciclada e das tintas não recicladas. Além destes parâmetros, também foram analisadas outras 
substâncias conforme a Norma Regulamentadora no. 15 do Ministério do Trabalho e Emprego (MTE, 2014). Porém, não foram diagnosticados valores representativos.

Tabela 1: Características da tinta reciclada (1) e não recicladas de cores preta (2) e branca (3)

\begin{tabular}{lccc}
\hline Parâmetro & $\mathbf{1}$ & $\mathbf{2}$ & $\mathbf{3}$ \\
\hline Aspecto & Cremoso & Cremoso & Cremoso \\
Densidade picnômetro $\left(\mathrm{g} / \mathrm{cm}^{3}\right)$ & 1 & 1,14 & 0,99 \\
Odor & Forte & Forte & Forte \\
Sólidos Suspensos $(\%)$ & 81 & 100 & 100 \\
Viscosidade $(\mathrm{cSt})$ & 152,34 & 159,89 & 156,73 \\
Bário $(\mathrm{mg} / \mathrm{L})$ & 42 & 35 & 56 \\
Chumbo $(\mathrm{mg} / \mathrm{L})$ & 0,152 & Isento & 0,1 \\
Cobre $(\mathrm{mg} / \mathrm{L})$ & 0,143 & 0,5 & 0,05 \\
Cromo Total $(\mathrm{mg} / \mathrm{L})$ & 0,016 & 0,001 & 0,01 \\
Ferro Total $(\mathrm{mg} / \mathrm{L})$ & 0,176 & 5 & 0 \\
Manganês $(\mathrm{mg} / \mathrm{L})$ & 94 & 114 & 78 \\
Sódio $(\mathrm{mg} / \mathrm{L})$ & 2.124 & 1.195 & 986 \\
Zinco $(\mathrm{mg} / \mathrm{L})$ & 7 & 15 & 5 \\
\hline
\end{tabular}

A tinta reciclada apresentou coloração cinza e o teor de sólidos suspensos (de $81 \%$ ) foi menor que os das demais tintas. A densidade foi bem próxima e a viscosidade foi menor. Mesmo a borra de tinta apresentando altos teores de sólidos, o processo de recuperação ocasionou uma boa dispersão das partículas, porém estas apresentaram visualmente tamanhos maiores do que das tintas não recicladas, podendo ocasionar pontos heterogêneos na camada de tinta aplicada no substrato após a secagem, prejudicando a qualidade da mesma. Dentre os metais analisados, na tinta reciclada, foram encontradas concentrações mais altas de chumbo, cromo total e sódio do que para as tintas não recicladas. Para os demais metais, as concentrações foram maiores que da tinta branca e menores que da tinta preta. A presença de metais, acima do permitido por legislação, como cádmio, chumbo e zinco é nociva à saúde dos profissionais que operam diariamente as cabines de pintura (Pimenta e Vital, 1994). Por outro lado, a presença de metais na composição das tintas aplicadas como revestimentos protetores é necessária, pois ajudam a inibir ou retardar o processo oxidativo das peças metálicas (Souza, 2009). A presença de chumbo na tinta reciclada, de 0,02\% (massa de chumbo/massa de sólidos da amostra), não exclui a possibilidade de uso como tintas de aplicação imobiliária, segundo a Lei $\mathrm{n}^{\mathrm{o}} 11.762$ (2008), que restringe esse valor a 0,06\% (m/m). Porém, há necessidade de estudos aprofundados para este caso.

\subsection{Ciclagem Térmica}

Na Figura 1 são apresentadas fotos de corpos de prova de aço comum e de $50 \%$ ferro nodular $50 \%$ ferro cinzento antes e depois do teste de ciclagem térmica. Não se constatou em nenhum dos corpos de prova testados, alterações na cor e aspecto da pintura, sendo as amostras aprovadas no teste. 


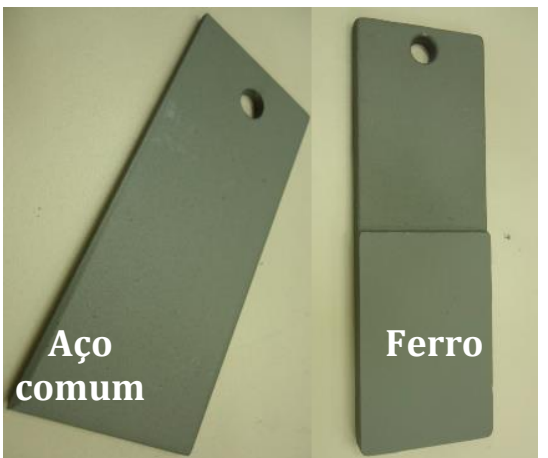

(a)

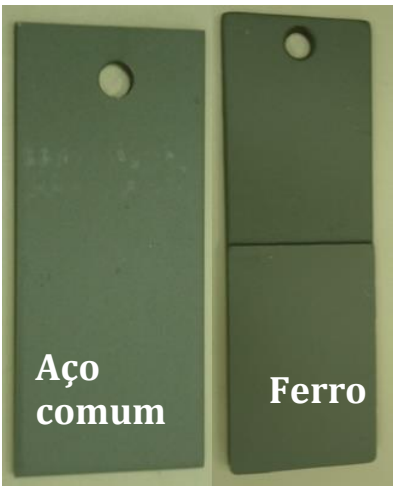

(b)

Figura 1: Corpos de prova em aço comum e ferro nodular/cinzento pintados com tinta reciclada (a) antes e (b) depois do teste de ciclagem térmica.

\subsection{Resistência à corrosão}

Todas as amostras dos corpos de prova testados foram aprovadas no teste de corrosão. No entanto, como comprovação, na Figura 2, estão apresentadas apenas as fotos dos corpos de prova de aço comum pintadas com a tinta reciclada.

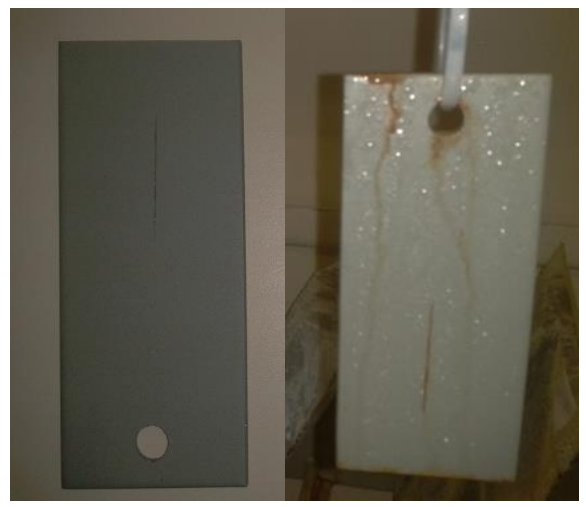

Figura 2: Corpos de prova em aço comum pintados com tinta reciclada antes e depois do teste de corrosão em névoa salina.

Observa-se que houve oxidação somente no corte, nas laterais e no furo de suporte usado para o gancho no ensaio, os quais não foram pintados com a mesma intensidade. No entanto, estas regiões não são consideradas na avaliação da qualidade da peça. Os resultados indicam que não houve migração do processo oxidativo da peça para a tinta reciclada durante o ensaio. As camadas de tinta depositadas sobre a peça formam um revestimento catódico pela presença de metais. Os elétrons positivos do corpo de prova tiveram apenas contato com os elétrons dos metais e metalógenos da tinta, impedindo que os mesmos tivessem contato com o meio exterior ao da película de tinta, diminuindo o processo de oxidação e aumentando a vida útil da peça. 


\subsection{Espessura de Camada}

Na Tabela 2 estão apresentados os resultados do teste de espessura de camada para os corpos de prova de aço comum pintados com tinta reciclada e não recicladas.

Tabela 2: Espessura de camada para os corpos de prova de aço comum pintados com tinta reciclada e não recicladas.

\begin{tabular}{lc}
\hline \multicolumn{1}{c}{ Amostra } & Espessura da camada $(\boldsymbol{\mu m})$ \\
\hline Tinta Reciclada 1 & 58,7 \\
Tinta Reciclada 2 & 58,2 \\
Tinta Reciclada 3 & 56,8 \\
Tinta Reciclada/Não Reciclada & 58,9 \\
Tinta Branca Não reciclada5 & 64,3 \\
Tinta Preta Não Reciclada & 60,2 \\
\hline
\end{tabular}

Todas as amostras pintadas com tinta reciclada (com duas demãos e como tinta de fundo) apresentaram camada com espessura média de 57,8 $\mu \mathrm{m}$, resultados esses próximos aos da tinta não reciclada de cor preta (de 60,2 $\mu \mathrm{m}$ ). Observou-se nas peças pintadas com tinta reciclada, que após a secagem, formaram-se pontos de elevação na película de tinta, oriundos das partículas sólidas de granulometria pouco maiores contidas na amostra. Desta forma, verifica-se que mesmo sendo aprovada nos testes anteriores, a tinta reciclada teria melhor uso como tinta de fundo.

\subsection{Aderência}

Na Figura 3 está apresentada foto do corpo de prova em aço comum pintado com tinta reciclada e submetido ao teste de aderência.

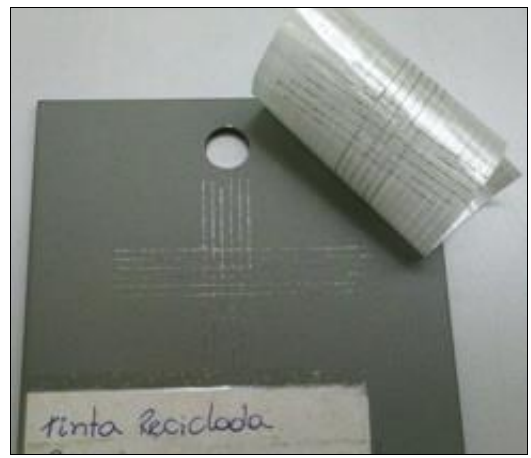

Figura 3. Corpo de prova em aço comum pintado com tinta reciclada após o teste de aderência. 
De acordo com a análise realizada conforme as informações e classificação da NBR11003/2009, a aderência da tinta reciclada foi classificada como 0 - Ótimo para um corpo de prova, pois não apresentou destacamento visível da película, e classificada como 1 - Bom para dois corpos de prova, devido ao teor de destacamento da película de tinta ter ficado em aproximadamente $5 \%$.

\subsection{Análise Econômica}

Os resultados da análise econômica estão apresentados na Tabela 3. Tomou-se como base a geração média de 12 toneladas por mês de borra de tinta na indústria.

Tabela 3: Análise econômica

\begin{tabular}{cc}
\hline Empresa & Custo (R) por tonelada \\
\hline Aterro Industrial & 375,00 \\
Transporte para aterro & 87,00 \\
Empresa de reciclagem + transporte & 300,00 \\
\hline Empresa & Custo $(\mathbf{R} \$)$ Anual \\
\hline Total Transporte + aterro industrial & $\mathbf{6 6 . 5 2 8 , 0 0}$ \\
Empresa de reciclagem + transporte & $\mathbf{4 3 . 2 0 0 , 0 0}$ \\
\hline
\end{tabular}

Uma vez que a borra de tinta a base de solvente é classificada como resíduo perigoso Classe I, isso acarreta em preços para a disposição final em aterro muito elevados. Em função disto, foram levantadas empresas de reciclagem deste tipo resíduo e a empresa escolhida situava-se no município de São José dos Pinhais- PR, cerca de $115 \mathrm{Km}$ de distância da indústria metalúrgica geradora dos mesmos. $\mathrm{O}$ aterro industrial localizava-se a 4,5 $\mathrm{Km}$ de distância da indústria. Foram negociados os custos efetivos para o transporte por empresa especializada o que tornou extremamente elevado o custo para o transporte deste resíduo somado ao custo da disposição em aterro industrial. A empresa de reciclagem apresentou licença para o transporte dos resíduos aliado aos equipamentos necessários para o mesmo. Ao negociar os valores de transporte e destinação da borra de tinta, a empresa optou por incorporar o custo de transporte ao custo de processamento da borra de tinta. Os custos para destinação em aterro industrial para dispor este resíduo em células foi significativamente alto, 35\% maior que o valor calculado para envio e recuperação pela empresa de reciclagem.

\section{CONCLUSÃO}

A tinta reciclada apresentou características e propriedades físicas e químicas semelhantes a tintas usualmente empregadas pela indústria metalúrgica, como as de cor preta. Todas as amostras pintadas foram aprovadas nos testes de ciclagem térmica, espessura de camada, aderência e corrosão, demonstrando que a tinta reciclada pode ser aplicada, porém como uma tinta protetiva de fundo, devido ao tamanho das partículas sólidas presentes. Testes complementares para usos com 
especificações mais restritivas são necessários. O processo de recuperação da borra de tinta empregado ainda não permite produzir tintas em cores variadas, uma vez que a borra é uma mistura de diferentes tonalidades de tintas. O método de reciclagem da borra de tinta empregado é um processo simples e apresentou menor custo em relação à disposição em aterro industrial.

\section{REFERÊNCIAS}

ABRAFATI - Associação Brasileira de Fabricantes de Tintas. Disponível em: http://www.abrafati.com.br/indicadores-do-mercado/numeros-do-setor/, acesso em março/2014.

BRITO, L. S.; CUNHA, M. E. T. Reaproveitamento de resíduos da indústria moveleira. UNOPAR Ciências Exatas e Tecnológicas, Londrina, v. 8, n. 1, p.23-26, 2009.

FAZENDA, J. M. R. Tintas e Vernizes: Ciência e Tecnologia. São Paulo: Ed. Abrafati - Associação Brasileira de Fabricantes de Tintas, $2^{\circ}$ Ed., Vol. 1 e 2, 1995.

JOHN, V. M. Reciclagem de resíduos na construção civil: Contribuição para metodologia de pesquisa e desenvolvimento. Tese de Livre Docência. Escola Politécnica - USP, 113 p., 2000.

JOHNSON, J. C.; SLATER, A. Method for treating waste paint sludge. Environment International, v. 17, n. 6, p. 22, 1991.

Lei 11.762, de $1^{\circ}$. de agosto de 2008, Diário Oficial da União, ISSN 1677-7042.

MTE - Ministério do Trabalho e Emprego. Norma Regulamentadora no. 15. Disponível em http://portal.mte.gov.br/legislacao/norma-regulamentadora-n-15-1.htm, acesso em abril/2014.

NBR 8.094 - Material metálico revestido e não-revestido - corrosão por exposição à névoa salina; Associação Brasileira de Normas Técnicas, 1983;

NBR10.004 - Resíduos Sólidos - Classificação, Associação Brasileira de Normas Técnicas, 2004.

NBR10.546 - Preparação de Corpos de Prova para aplicação de tintas, Associação Brasileira de Normas Técnicas, 1988;

NBR11.003 - Tintas - Determinação da aderência, Associação Brasileira de Normas Técnicas, 2009;

NBR13.006 - Pintura de corpos-de-prova para ensaios de tintas, Associação Brasileira de Normas Técnicas, 1993;

PIMENTA, A. S.; VITAL, B. R. Contaminação de pintores profissionais por metais pesados provenientes de tintas e vernizes, Química Nova, v. 17, n. 4, p. 277-280, 1994. 